\section{British Water Research Association}

The fourth annual report of the Water Research Association covers the year ended June 30, 1959, and includes the reports of the Council and of the director of research, Dr. R. G. Allen, together with lists of staff and of members (pp. $31+4$ plates. Redhill : Water Research Association, 1959). The Association's application for a grant from the Department of Scientific and Industrial Research was approved in February for the five years commeneing 1959 , at $£ 15,000$ a year, conditional on a minimum of $£ 30,000$ being raised by the industry, with up to a further $£ 12,000$ a year on the basis of $£ 80$ for every further $£ 100$ of membership income. In his report, the director again refers to the studies of the effect of $p \mathrm{H}$ on the coagulation of dilute colloidal dispersions of clay minerals, which have indicated that except for the bentonites, which can be coagulated with low doses of aluminium sulphate at all $p H$ values below $7 \cdot 5$, the amount of aluminium sulphate required to effect coagulation is at a minimum about $p \mathrm{H} 6 \cdot 8-7 \cdot 5$. Work on the isolation of suspended colloidal matter in rivers using a continuously operated centrifuge is virtually complete, and a comprehensive investigation has been commenced on the effect of various factors in the preparation of activated silica. Other work has included the effect of physical variants on coagulation, the absorptiometric determination of aluminium, the leaching of lead stabilizers from polyvinyl chloride pipes and the determination of the permeability of plastic pipes to coal gas.

\section{Museum of Applied Arts and Sciences, Sydney}

Is common with most museums and art galleries the institution at Sydney is greatly in need of additional buildings to enable the Trustees to fulfil their obligations to the public. Lack of amenities for both visitors and staff, as well as inadequate facilities for exhibition, storage and preparatory work, was causing concern, and disappointment was expressed at the delay in implementing plans for improvement. Recently, however, some progress has been made and plans have been prepared for an extension to the present building and negotiations have started to take over an existing building on a neighbouring site for the storage and display of heavy machinery and transport exhibits. It is the aim of this Museum to show the latest trends in technology and thus provide inspiration and ideals for local manufacturers and others interested. To do so the staff must study developments in science at world research centres and by continuous contact endeavour to obtain specimens and relevant information regarding examples of applied science (Annual Report of the Trustees of the Museum of Applied Arts and Sciences, Sydney, for the year ended 31st December, 1958. Pp. 19. Sydney: Museum of Applied Arts and Sciences, $1960)$.

\section{New Mineralogical Periodicals}

THE formation last year of the Mineralogical Society of India has been quickly followed by the publication of The Indian Mineralogist, to be issued by the Society half-yearly as a medium for articles on crystallography, mineralogy, petrology, and allied subjects (Editorial Office : Department of Geology, A.C. College, Madras 25 ; price 10 R. per annum). The first number (Part 1, 1960) comprises twelve articles in 107 pages, most by Indian workers but a few contributed by Scandinavian and Australian mineralogists. If the initial standard is maintained, the journal will become one of international reputation and the Society should readily enlarge its present membership of 160 , mainly resident in Southern India. Simultaneously, a new Russian journal has been issued by the East Siberian Division of the AllUnion Mineralogical Society (Zapiski VostochnoSibirskogo Otdeleniya V sesoyuznogo Mineralogicheskogo Obshchestva, Academy of Sciences, Moseow : Vol. 1. No. I, 1959. Pp. 130. price 7r. 30k.), concerned principally with the topographical mineralogy of the territories east of the Urals. The eastward drift of Soviet geological-mineralogical interests is reflected also in the establishment this year of a new Geochemical Institute and Laboratory for Isotope Geology in the town of Irkutsk, administered by the Siberian Division of the Academy of Sciences, and one can expect that there will be no shortage of important contributions to the new periodical.

\section{Compilation of Russian Journals}

UNDER the title "Russian Journals", a union list of titles of 54 such periodicals held by four libraries in Manchester and Salford has been compiled for the benefit of scientists, research workers, students and librarians (pp. 14. Library Association: North Western Group. Reference, Special and Information Section. Manchester : Central Library, 1960). In an introduction, Mr. L. L. Ardern, under whose direction the list has been compiled, indicates that the Secretary of the Group will be glad to have details of other Russian titles held by other libraries in the area and to add these to a union list on cards held by the Regional Library Bureau. The entries are listed in alphabetical order of the Russian title, under the society's name if the periodical is published by a society. There is a full index under translitorated and translated titles. The participating libraries are those of the Manchester College of Science and Tech. nology, University of Manchester, Royal Technical College, Salford, and Manchester Public Libraries.

\section{Chromosome Abnormalities in Man}

IN a recent issue of Science Progress (48, No. 190 , April 1960) Dr. C. O. Carter points out that the year 1959 will be remembered for an important breakthrough in the science of human genetics. This was the discovery that certain congenital abnormalities in man are due not to 'point mutations', that is mutations involving only a tiny fragment of a chromosome, but to the addition or loss of whole chromosomes. Most mutations in animals and plants are 'point' mutations, and no change is apparent on examining chromosomes. Some mutations, however, are accompanied by visible changes in the chromosome. These vary from the addition or loss of whole chromosomes to the addition or loss of a small fraction of a chromosome. Investigation has shown that loss of an appreciable fragment, say, a fifth, of an average-sized chromosome is not compatible with life. The presence of extra fragments of chromosome, however, is better tolerated, though resulting in some degree of abnormal development, and in plants a number of examples of individuals with one extra chromosome have been studied. These 'trisomics' have the chromosome number $2 \mathrm{n}+1$, and one ehromosome is present in triplicate, not paired. 